\title{
Development Path for Regional City News in Merge Medias
}

\section{-Observe "Yunnan Information News" Digital 2015 Redesign}

\author{
Yuqing Xiao \\ Journalism Schools in Xihua Normal University, Nanchong, China \\ Email: 674335141@qq.com
}

Received 31 May 2015; accepted 28 June 2016; published 2 July 2015

Copyright (C) 2015 by author and Scientific Research Publishing Inc.

This work is licensed under the Creative Commons Attribution International License (CC BY).

http://creativecommons.org/licenses/by/4.0/

c) (i) Open Access

\begin{abstract}
With the development of communication technology, media integration has been a main trend in today's media development. As the active Metropolitan news in the reform of Chinese newspaper industry, it is worth exploring how to survive and develop under the background of media convergence. The writer thinks different Metropolitan news with different cultural backgrounds and media powers has different integration features. The article regarded "Yunnan information news" digital 2015 redesign as the observed sample to analyze the development path of regional metropolis daily in the background of media integration.
\end{abstract}

\section{Keywords}

\section{Media Integration, Yunnan Information News, Development Path}

\section{Introduction}

McLuhan has realized the appearance of new media couldn't completely replace old media in the 1960s to 1970s, Instead, the old and new media coordinate with each other to build a new media ecological environment, so as to fulfil the process of the media coexist communion of the old and the new [1]. The earliest concept of media integration is put forward by Professor Bijapur in Massachusetts Institute of Technology, which means each kind of media presents the trend of multifunctional integration. Another American scholar Andrew Nachison defined media integration as strategic, operational and culture union of printed, audio, video, and interactive digital media organization. In the trend of media integration, the survival and development of Metropolitan newspapers had great changes. Interactive and fragmentary spread had replaced the traditional linear transmission and one-way transmission. 
The article regarded "Yunnan information news" digital 2015 redesign as the observed sample to analyze the development path of regional metropolis daily in the background of media integration. The writer thinks only Metropolitan newspapers keeps to the development rules of fusion equal communication media and interactive communication, with the form of exchanging information actively the Internet and new media, and with the content of developing delicate and contract information products, can a metropolitan daily find a way suitable for its own development path..

\section{Revision Changed for "Yunnan Information News" in 2015}

"Yunnan information news" was set up in 1985, then had cooperative revision with "Chengdu Commercial Daily" in 1999 and had combined revision between Nanfang media group and Yunnan publishing group in 2007, which gradually reflected bright, lively and rigorous style due to constantly reform that were favored for social elites in Kunming and Yunnan. In 2015, "Yunnan information news" tried to overturn traditional daily reading to be sorted again in forms and contents combined with reading features at the age of Internet. The new revision of "Yunnan information news" further highlighted the point of view, differentiation, intensive reading and efficiency in the editing concept, and divided into A pile of news weekly fold folding + B folding life in layout structure. A pile of news weekly fold folding divided into three units, which are light reading, deep reading and pleased reading in accordance with concept of useful reading and practical. Let users access to news, information, and ideas easily through a simple and easy-to-read news display method.

\subsection{Easily and Readable Discourse Transformation}

American postmodern theorists Jameson thought cultural characteristics for modern social were multi-ethnic, no center, anti-authority, narrative, trivializes situated and no depth [1]. Media culture guided by Internet new media were complied with the feature that communication content had characteristics of immediacy and fragmentation to make spreaders release, modify, add, delete, and update information as their wishes, and disseminators and recipients instantly interacted to jointly build information network. Audiences for traditional media changed into personalized and involved media users who more preferred the spread approaches with fun and simple. The changes of spread information environment and demand to make metropolitan news must find transformation of discourse [2].

"Yunnan information news" made 2 to 6 versions in A pile set up slight reading and set up attitude, face, maps, world and relevant versions in below. The small columns of "an article", "a reading” and "a scan" set in the revision of "slight reading and attitude" also adapt the information aggregation method in new media time to create tiny and pithy news contents. The column of "an article" general selects an important comments in day's Xinhua news agency or newspaper office, which words are short and simplify. The column of "a reading" timely select two or three popular Weibo to comment on current events. For example, "a reading" selects the three Weibo sayings of @ Cao Lin of China Youth News, @ People’s Daily and @ leave a few hands on January 21, 2015 to give opinion of pensions reformed, an old man beat doctors in hospital and mother forced abortion. The column of "a scan" scans foreign and domestic important news in recently, which explains key elements, the core focus and news background with a few sentences to make readers control point views in a short span of time. The designs in version also use print layout characteristics to use bold, colored fonts to highlight importance (see Figure 1). "Slight reading and face" released news information with the method of highlighting newsmakers. Each short information all had configuration of news image features. "Slight reading and map" marked the news site on the map in Kunming with concise memo type messages to highlight news sites and let the reader know clearly about the orientation of news occurred (see Figure 2).

\subsection{A Large Number of Data News and Visual News}

At present, the widely application of data had penetrated into every area of society that some domestic and foreign mainstream media started to try to appear news using the reporting approach of data news. Data news revealed key associated factors according to data quantitative analysis to help users to better understand the happening news. From the point of communicating effect, the sides of conveying information and attracting users of data news are more effective than traditional written reports.

"Yunnan information news" set up "deep reading” to generally make ten versions with the contents of blockbuster, current political situation, interpretation, character, scene, survey, wealth and new historical records. The 


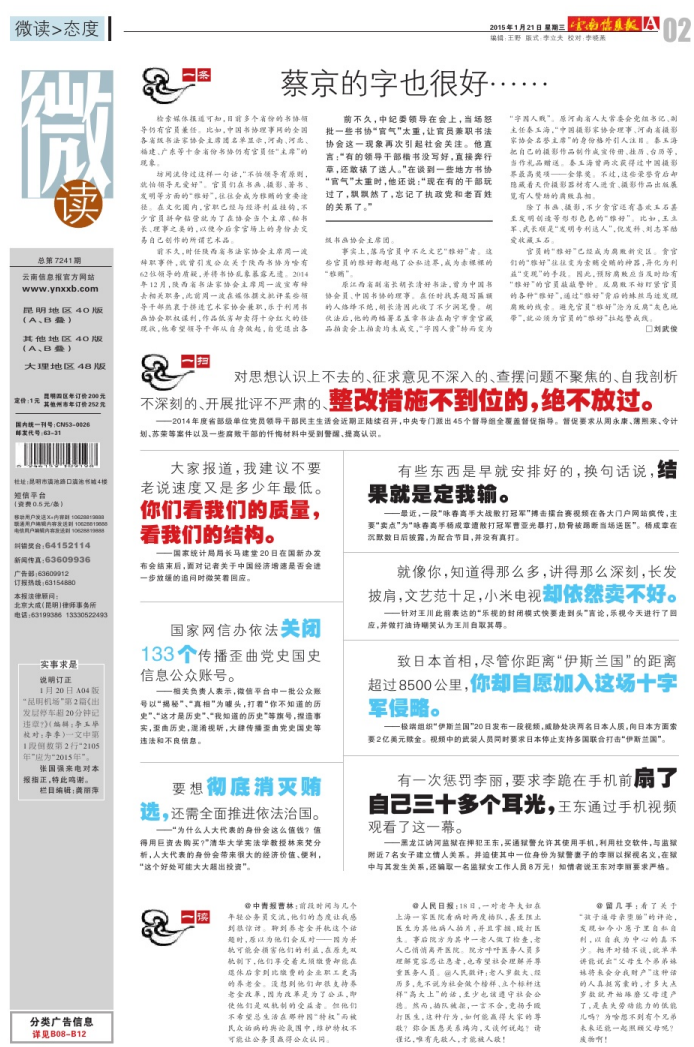

Figure 1. From the "Yunnan information news" January 21, 2015 A02 version.

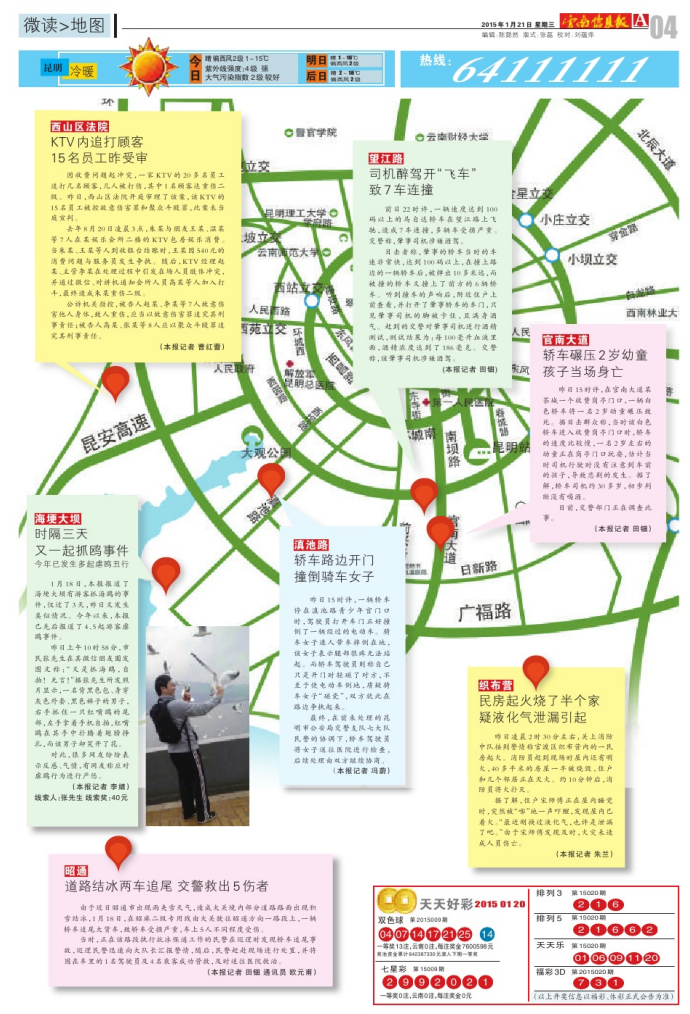

Figure 2. From the "Yunnan information news" January 21, 2015 A04 version. 
news story of the version often involved government news. Though they are related to people's vital interest, it is difficult to catch people's eyes from the general situation. In the background of media integration, metropolis daily must use simple and flexible approach to unscramble policies to make full use of chart, data, comic and other page elements. The content of "deeply reading and current political situation" for A12 on January 27, 2015 is an interpretation of Yunnan CPPCC report in 2015. Designed of the whole page is map in Yunnan to mark important factors of six new industry district and city, Yunnan province and 129 counties into government work report (see Figure 3). The news sites were highlighted with blue fonts. Some important events like Jade in the grinding, auspicious, MiMeng, xu bi (Yunnan) railway project, lugu lake, cangyuan, lxa airport construction, LuDian, Yingjiang and Jinggu earthquake were displayed with abstract to make the whole layout concise and easy to read. "New opportunities", "new development", "new power", "new breakthrough", "new environment" and "new image" in A13-A19 focused the investment of transportation, industry, people's livelihood, pension, health, home economics and other industries with impressions of key terms, data, comic book (see Figure 4).

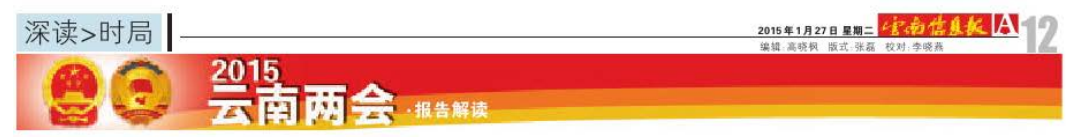

\section{为什么这些地方被写入政府报告?}

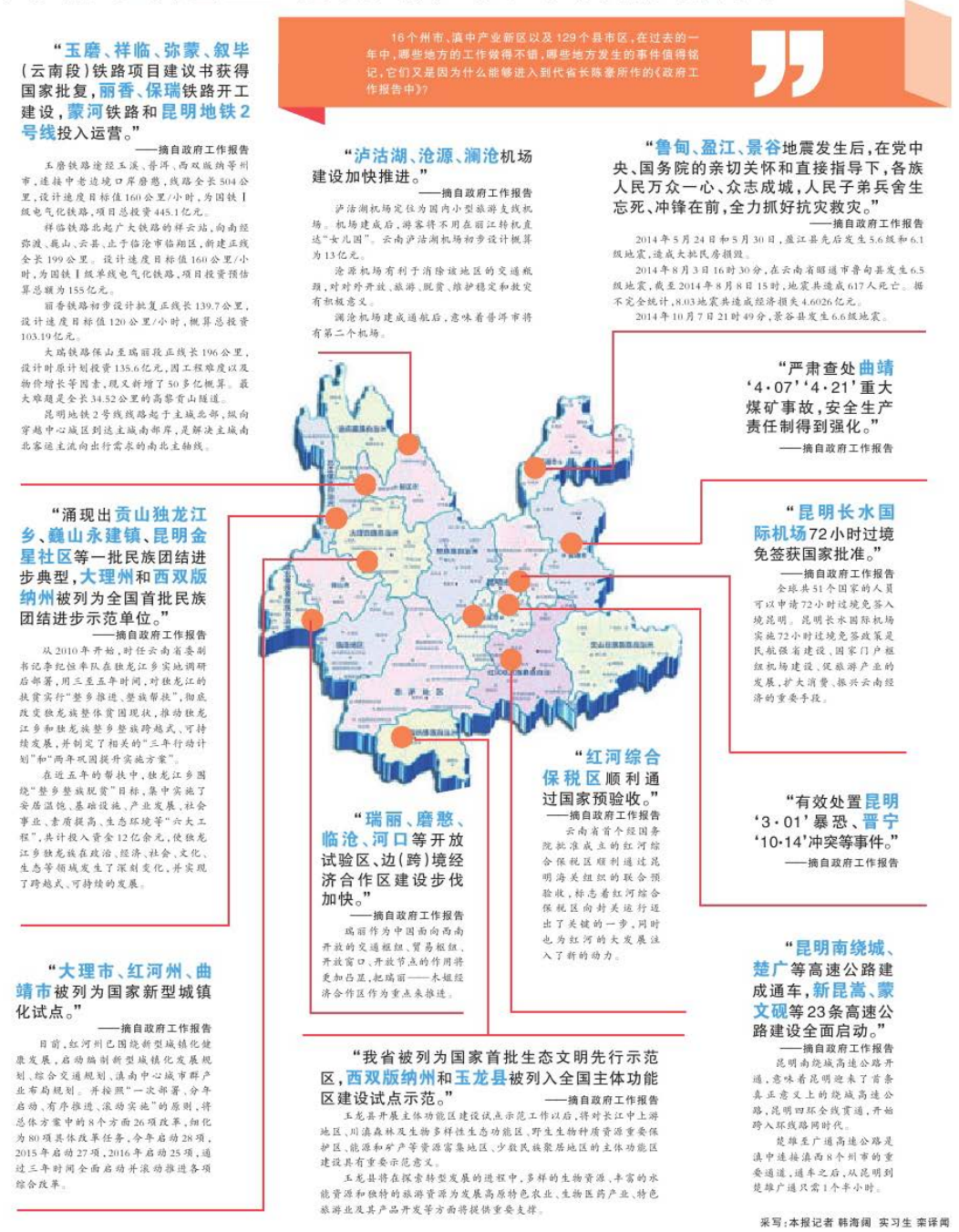

Figure 3. From the "Yunnan information news" January 27, 2015 A12 version. 


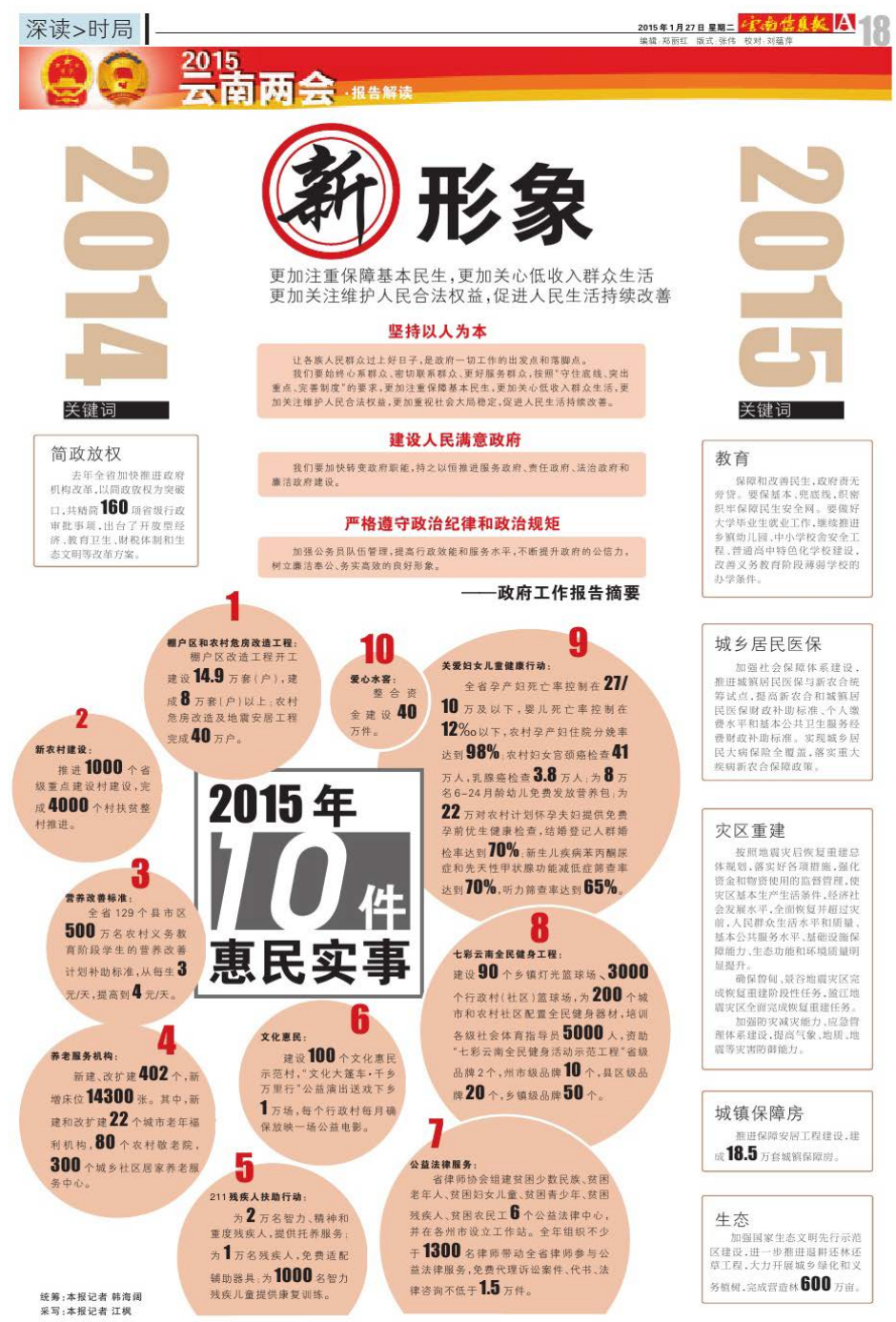

Figure 4. From the "Yunnan information news” January 27, 2015 A18 version.

\subsection{Continue with Regional Culture}

The impact force of era development to regional culture had far beyond people's imagination. Social life, history and legend, national migration, customs, customs and family life carried by regional culture had neglected in modern media. For the speed reading context in modern media, the historical heritage and cultural resources become scarce resources. In this sense, regional metropolis daily has advantages in the development of regional culture inheritance.

Yunnan is a civilian area for minorities in borderland, which has rich natural resources and a variety of folk customs. All the time, "Yunnan information news" ever pushed out numerous large coverage and column to introduce Yunnan according to strong backing in southern company, which has a good local voice to present regional cultures. The beauty of nature, humanity and nation for Yunnan get full displayed on the metropolis daily pages. New "Yunnan information news" continue to give power in the page of culture to push out "Earth Weekly”, "Culture Week”, “Movie Magazine”, "Happy Reading” and other monographs to develop local cultural market and expand brand influence.

\subsection{News Compatible with the Service Platform}

In the open Internet era, news report is a completed works on the surface and in the fact is a huge writable text 
that can add new information. Electronic metropolis daily is not just a newspaper, a few metropolis news are all develop website, weibo, micro, APP and other information and services functions.

For the website of "Yunnan information news", there are hot comments to the bottom of page of news link to allow net friends to have direct comments and forward websites and micro in timely. Not only net friends are news consumers, but also become productivity of the news. They can participate in news production by method of commenting, voting, forwarding, interaction for news. They also can read composing platform for numerous kinds of messages like rolling news, special news, buy houses, BBS, ranking, strategy and other services. The hypertext structures changed linear structure of traditional newspapers in a certain extent to realize combination of multimedia technology [3].

\section{Inspiration of Metropolis Daily Development in Merge Medias}

On July 21, 2014, the $34^{\text {th }}$ report published by CNNIC showed scale of Chinese net friends up to 632 million as of June 2014 that including 527 million of mobile Internet users. Development of metropolitan daily must be followed rules of the development of the new media, strengthened integration thought to carefully develop individuation and differentiation media products [4].

\subsection{Cored by Internet}

Chinese scholars Peng Lan ever expressed that media don't have to regarded as final carrier of various kinds of media products, but rather can regarded as transmission channel. The method not only can inherit inherent form advantages for traditional media products, but also can adapt existing network information receiving habits for audiences. Integration between network and traditional media can greatly expand speed and breadth in the side of transmission of information channel. By the development of network technology, it is well known for industry that future of the newspapers existed by digital online edition. Metropolitan Daily ought to set up new production mechanism taking internet as core.

\subsection{Integration Thought}

The core of media integration is to aggregate media information to provide the most important and essential contents for users. From the point of view of content production, metropolitan daily can integrate advantages of multimedia text, great influence of paper media and characteristic of Internet real-time interaction to build unique and delicate news products to meet multilevel information demand for users. The diversity of transmission channels decides shift transmission concept for metropolis daily to use Micro blog, we Chat and other numerous kinds of media terminal to expand wider spread market.

\subsection{Highlight Local Characteristics}

Fission development for media technology brings unlimited expansion of information to make people too hard to digest such a large information capacity in the limited time and space. Screening and reconstruction for customizing messages became one of the services functions for today's media. Location for metropolitan news must hold the function of localizing serviced, which start from meet the demand of local people and use regional characteristics to initiate regional exquisite news to give full play to the media function of widely contact with masses.

\subsection{Optimization of Reading Form}

Leap of media quantity makes people's life rhythm fast that received ideas and ways for audiences have changed. In the reading environment, paper media needs to develop more layout forms of conveying information with visual sense of beauty to meet users' requirement of happy reading. The adopted methods are magazine-type cover, visualization page layout, data-type news, classifying information and diversification.

\section{Conclusion}

The media environment scholar Paul Levin so thought media would develop towards the trend of more and more humanized. Whatever medium form or production contents, they will be more convenient to meet personalized 
requirements. In this era of connected media convergence, a regional metropolitan daily needs to refind the habits and rules of how the target users receiving information, in order to make quality and integrated news products, and to expand more development space.

\section{References}

[1] Gong, C.B., Ed. (2011) Introduction to Media Fusion. China Radio and TV Press, Beijing, 74.

[2] Wu, D.H. (2010) In the Fit of Shallow Reading and Deep Reading for the Newspaper Survival Strategies. Journalist, 5, 18-21.

[3] Huang, C.X., Ed. (2011) Media Innovation in the Background of Media Convergence. Zhejiang University Press, Hangzhou.

[4] Zhan, X.H. and Yang, A.J. (2014) Development and Innovation for Internet in 2014. Youth Journalist, 24, $20-22$. 